\title{
Answer to the readers of "Successful radiofrequency ablation strategies for benign thyroid nodules"
}

\author{
Ji Young You ${ }^{1} \cdot$ Da Won Park ${ }^{1} \cdot$ Hoon Yub Kim ${ }^{1}$
}

Received: 2 July 2019 / Accepted: 19 July 2019 / Published online: 31 July 2019

(c) Springer Science+Business Media, LLC, part of Springer Nature 2019

Sabri Ozden et al. showed interest in our paper entitled "Successful radiofrequency ablation strategies for benign thyroid nodules" [1].

At first, they asked to objectify the subjective findings of symptoms. We suggested the following as indicative symptoms to perform the procedure: compressive symptoms, neck discomfort or phonation symptoms. For checking compressive symptoms and neck discomfort, we used patient questionnaires. At the patients' first visit to hospital, they were divided into three groups according to their discomfort from the throat symptoms: very uncomfortable, uncomfortable, and asymptomatic. Phonatory symptoms included hoarseness, vocal straining, vocal fatigue, lump sensation and aphonia. These symptoms were collected via patient questionnaires at their first visit to hospital. The Voice Handicap Index was not assessed.

The other query was regarding why the RFA was put forward as a treatment of choice rather than ethanol ablation, which seems to be more safe and effective. As per the current guidelines for benign thyroid nodules [2], percutaneous ethanol injection is preferred to treat cystic nodules because of its low price, but it is not established to cover predominantly solid nodules. Radzina et al. reviewed the literature to evaluate indications, techniques, complications and limitations, and assessed the outcomes for benign, solid, partially cystic nodules and recurrent malignant nodules [3].

RFA has been commonly reported to have disadvantages that include its high cost and technical operating challenges. Especially, there are frequent inquiries regarding the medical cost associated with RFA. Since the public (national) and private medical insurance systems are well established in South Korea, the patient could face a minimal financial

Hoon Yub Kim

hoonyubkim@gmail.com

1 Department of Surgery, KUMC Thyroid Center, Korea University Hospital, Korea University College of Medicine, Seoul, Korea burden if they undergo RFA, thereby not limiting the patient's options. For this reason, RFA is actively performed not only in the thyroid gland but also in liver diseases, and RFA is easy because there is a considerable number of practitioners having sufficient experience. Therefore, despite the few drawbacks, RFA could have sufficient advantage over PEI at least in Korea.

In conclusion, we re-confirm that RFA of benign thyroid nodules may be feasible and safe with low complication rates when performed by an experienced thyroid surgeon even in predominatly cystic nodules.

\section{Compliance with ethical standards}

Conflict of interest The authors declare that they have no conflict of interest.

Publisher's note: Springer Nature remains neutral with regard to jurisdictional claims in published maps and institutional affiliations.

\section{References}

1. G.M. Lee, J.Y. You, H.Y. Kim, Y.J. Chai, H.K. Kim, G. Dionigi, R.P. Tufano, Successful radiofrequency ablation strategies for benign thyroid nodules. Endocrine 64(2), 316-321 (2019). https:// doi.org/10.1007/s12020-018-1829-4

2. J.H. Shin, J.H. Baek, J. Chung, E.J. Ha, J.H. Kim, Y.H. Lee, H.K. Lim, W.J. Moon, D.G. Na, J.S. Park, Y.J. Choi, S.Y. Hahn, S.J. Jeon, S.L. Jung, D.W. Kim, E.K. Kim, J.Y. Kwak, C.Y. Lee, H.J. Lee, J.H. Lee, J.H. Lee, K.H. Lee, S.W. Park, J.Y. Sung; Korean Society of Thyroid R, Korean Society of R, Ultrasonography diagnosis and imaging-based management of thyroid nodules: Revised Korean Society of Thyroid Radiology Consensus Statement and Recommendations. Korean J. Radiol. 17(3), 370-395 (2016). https://doi.org/10.3348/kjr.2016.17.3.370

3. M. Radzina, V. Cantisani, M. Rauda, M.B. Nielsen, C. Ewertsen, F. D'Ambrosio, P. Prieditis, S. Sorrenti, Update on the role of ultrasound guided radiofrequency ablation for thyroid nodule treatment. Int J. Surg. 41(Suppl 1), S82-S93 (2017). https://doi.org/10.1016/j. ijsu.2017.02.010 